\title{
Metabolic predictors of middle-distance swimming performance
}

\author{
J.P. Ribeiro, MD, ScD, E. Cadavid, MD, J. Baena, MD, E. Monsalvete, MD, A. Barna, MD \\ and E.H. De Rose, MD \\ Exercise Research Laboratory, Federal University of Rio Grande do Sul, Porto Alegre, Brazil
}

\begin{abstract}
To evaluate the capacity of different metabolic indices to predict performance in middle distance swimming, 15 competitive swimmers performed a submaximal and a maximal 400 metres freestyle swimming event. Expired gases were collected in Douglas bags immediately after the events for the determination of $\mathrm{VO}_{2} \max$. Arterialized blood samples were collected for the determination of maximal blood lactate concentration and the velocity corresponding to blood lactate concentration of $4 \mathrm{mM}$. The results demonstrated (means $\pm S D$ ): maximal velocity of $1.44 \pm 0.05 \mathrm{~m} . \mathrm{s}^{-1}$; velocity at 85 percent of $\mathrm{VO}_{2} \max$ of 1.36

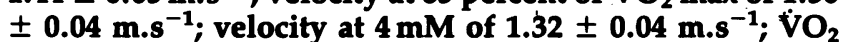
$\max$ of $3.47 \pm 0.51 . \mathrm{min}^{-1}$; maximal blood lactate concentration of $11.8 \pm 2.5 \mathrm{mM}$. Multiple regression analysis relating metabolic indices and maximal velocity demonstrated that only velocity at 85 percent of $\mathrm{VO}_{2}$ max $\left(r^{2}=0.81\right)$ and velocity at $4 \mathrm{mM}\left(r^{2}=0.79\right)$ were significant predictors. Thus, 79 percent of the variance in the performance of $400 \mathrm{~m}$ freestyle can be accounted for the velocity at 85 percent of $\dot{\mathrm{VO}}_{2}$ max or the velocity at $4 \mathrm{mM}$. The success in this event seems to depend on the swimmer's capacity to achieve higher velocities with lower blood lactate levels and/or utilizing a lower percentage of their $\mathrm{VO}_{2}$ max.
\end{abstract}

Keywords: Maximal oxygen uptake, anaerobic threshold, blood lactate

It has been repeatedly shown that performance in long distance running and cycling is closely related to the individual's maximal oxygen uptake $\left(\mathrm{VO}_{2} \max \right)$, to the percentage of $\mathrm{VO}_{2}$ max taxed during the event, and to ventilatory or lactate thresholds ${ }^{1-8}$. However, these findings cannot be generalized to swimming due to the great variability in the swimming economy among different swimmers 9 . Costill et al. ${ }^{10}$ found a poor correlation between $\mathrm{V}_{2}$ max and the performance in the 365.8 metres freestyle event, while Olbrecht $e t$ al. found a high correlation between the swimming velocity corresponding to the blood lactate concentration of $4 \mathrm{mM}$ and the performance on a 30 minute swimming event ${ }^{11}$. The 400 metres freestyle is an event in which both aerobic and anaerobic processes contribute to the energy release. However,

Address for correspondence: Jorge Pinto Ribeiro, Laboratorio de Pesquisa do Exercicio, Universidade Federal do Rio Grande do Sul, Rua Felizardo 750, 90610 Porto Alegre RS, Brazil

(C) 1990 Butterworth-Heinemann Ltd

0306-4179/90/030196-05 little is known about the value of different metabolic indices in the prediction of performance in this event ${ }^{12}$.

This lack of data may be related to the fact that evaluation of the energy releasing processes in swimming is difficult to perform in most exercise physiology laboratories. However, new methods have been developed which allow the determination of $\mathrm{VO}_{2}$ and blood lactate concentration in response to different swimming velocities with the collection of expired air and blood samples in the recovery period $^{13,14}$. These methods present the advantage of estimating the contribution of anaerobic and aerobic processes at submaximal and maximal intensities while swimming, and relating these findings to training intensities ${ }^{10,15}$. Thus, the present study was conducted to evaluate the capacity of metabolic indices derived from these new methods to predict the performance in the $\mathbf{4 0 0}$ metres swimming event. The results indicate that some of these factors may be important determinants of middle distance swimming performance.

\section{Method}

Fifteen competitive swimmers participated in the study. Their physical characteristics are described in Table 1. They were participating in intense physical training, they were all used to swimming the 400 metres freestyle swimming event, but not all of them were specialists in such an event. The athletes were informed about the risks involved in the participation in the experiments and signed an informed consent.

Table 1. Physical and performance characteristics of swimmers

\begin{tabular}{|c|c|c|c|}
\hline & Mean & $S D$ & Range \\
\hline $\begin{array}{l}\text { Age (years) } \\
\text { Weight }(\mathbf{k g}) \\
\text { Height }(\mathrm{cm}) \\
\text { Lean body mass }(\mathbf{k g}) \\
\text { Water temperature }\left({ }^{\circ} \mathrm{C}\right)\end{array}$ & $\begin{array}{c}16 \\
63 \\
171 \\
56 \\
28.5\end{array}$ & $\begin{array}{l}2 \\
8 \\
4 \\
7 \\
0.6\end{array}$ & $\begin{array}{c}13-19 \\
50-79 \\
159-185 \\
44-69 \\
27-29\end{array}$ \\
\hline $\begin{array}{l}\text { Velocity submax }\left(m . s .{ }^{-1}\right) \\
\text { Velocity } \max \left(\mathrm{m}^{-1} \mathrm{~s}^{-1}\right) \\
\text { Velocity } 4 \mathrm{mM}\left(\mathrm{m}^{-1} \mathrm{~s}^{-1}\right) \\
\text { Velocity } 85 \% \mathrm{VO}_{2} \max \left(\mathrm{m}_{\mathrm{s}} .^{-1}\right)\end{array}$ & $\begin{array}{l}1.34 \\
1.44 \\
1.32 \\
1.36\end{array}$ & $\begin{array}{l}0.05 \\
0.05 \\
0.04 \\
0.04\end{array}$ & $\begin{array}{l}1.26-1.41 \\
1.35-1.54 \\
1.25-1.37 \\
1.30-1.43\end{array}$ \\
\hline
\end{tabular}


At least 12 hours after the last training session, each swimmer performed two 400 metres freestyle swimming trials in an indoor swimming pool 25 metres long, according to the protocol described by Costill et al. ${ }^{10}$ and Olbrecht et al. ${ }^{11}$. These trials were preceded by a warm-up period in which the athletes swam to get used to the swimming pool. The water temperature was maintained between 27 and 29 degrees centigrade, and the events were performed with a 20 minute interval period in which the swimmers remained seated out of the water.

In the first trial the athletes were asked to swim at a constant velocity in order to achieve 90 percent of their maximal velocity for the event. On the second trial the swimmers were asked to achieve their best time for the event. The subjects who could not achieve these goals came back on another day to swim at the appropriate velocities. During the recovery period of each trial, expired gas and blood samples were collected to evaluate the metabolic indices.

One stroke before the end of the events, the swimmers retained their breath, exhaling the air in a three-way respiratory mask as soon as the operator put it on their faces ${ }^{10}$. The face mask was connected by a short tube to a Douglas bag. The expired gas was collected over the first 20 seconds of the recovery period. Afterwards, air samples from the bags were collected in oiled syringes for analysis of $\mathrm{O}_{2}$ and $\mathrm{CO}_{2}$ concentration by the Sholander technique ${ }^{16}$, and the expired volume was measured in a dry gas meter. Conventional formulas ${ }^{17}$ were used to calculate the oxygen uptake for the submaximal $\left(\dot{\mathrm{VO}}_{2}\right.$ submax $)$ and maximal ( $\mathrm{VO}_{2}$ max) events. No correction was made for the backward extrapolation ${ }^{18}$ of these values because all subjects were studied in the same conditions. The results obtained from this method have been shown to be valid and reproducible ${ }^{10,13,18}$.

$\mathrm{VO}_{2}$ max was expressed in $1 . \mathrm{min}^{-1}$, considering the body mass in $\mathrm{ml}$.(kg.min $)^{-1}$, and considering the lean body mass estimated by skinfold thickness ${ }^{19}$ in ml.(kg LBM.min) ${ }^{-1} \cdot \dot{\mathrm{VO}}_{2}$ submax was expressed in 1. $\min ^{-1}$ and as a percentage of $\dot{\mathrm{VO}}_{2} \max$. The results of $\dot{\mathrm{VO}}_{2}$ max and submax were plotted as a function of the swimming velocity in each of the events so that the velocity corresponding to 85 percent of $\dot{\mathrm{VO}}_{2}$ max could be interpolated or extrapolated for each individual. Figure 1 illustrates this procedure for two of the swimmers.

Twenty microlitre arterialized blood samples were collected from the ear lobe immediately before the events and at one, three and five minutes in the recovery period for later analysis in duplicate by a modified enzymatic method ${ }^{20}$. The samples were deproteinized in 200 microlitres of perchloric acid and centrifuged for five minutes at $12000 \mathrm{rpm}$. Fifty microlitres of the supernatant were pipetted in 500 microlitres of a glycine hydrazide buffer solution, 50 microlitres of a NAD solution, and five microlitres of a lactate dehydrogenase solution. The assay was incubated for 60 minutes at 25 degrees centigrade, and the absorbance was read in a spectrophotometer at $364 \mathrm{~nm}$. In our laboratory, the coefficient of variation for two samples is 4.5 percent for resting

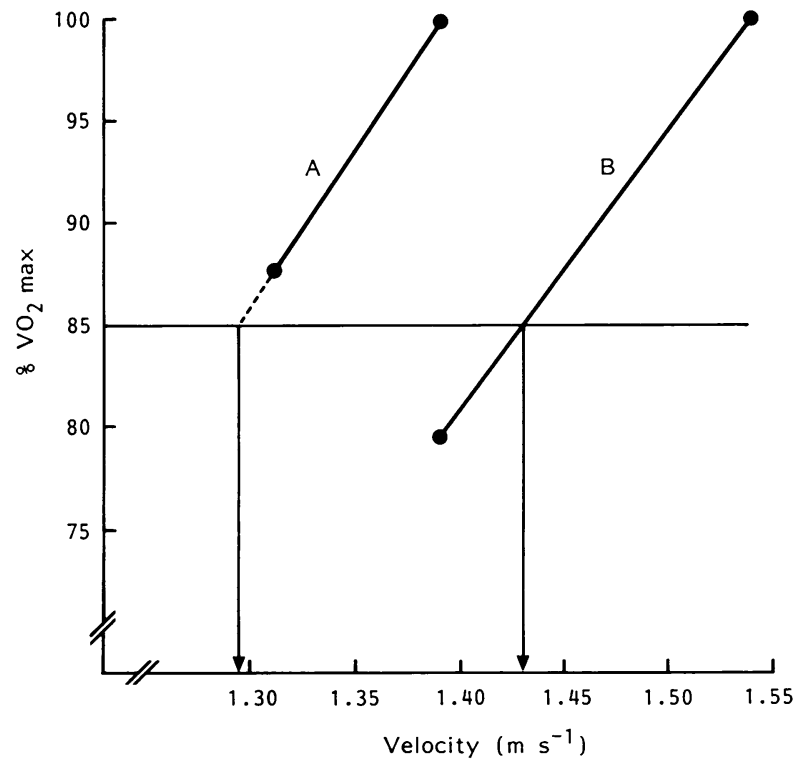

Figure 1. Percentage of $\dot{\mathrm{VO}}_{2}$ max related to swimming velocity in two of the swimmers. For swimmer $A$ the velocity corresponding to 85 percent of $\dot{V}_{2}$ max was extrapolated and for swimmer $\mathrm{B}$ it was interpolated. $\mathrm{V}_{2}$ max in swimmer $A$ was $3.491 . \mathrm{min}^{-1}$, which corresponded to $60 \mathrm{ml}$.(kg.min) ${ }^{-1}$. VO $_{2}$ max in swimmer $B$ was 3.09 I. $\mathrm{min}^{-1}$, which corresponded to $50.9 \mathrm{ml}$.(kg.min) ${ }^{-1}$.

and 5.1 percent for exercising conditions. The highest blood lactate concentration in the recovery period was used as the representative for each swimming velocity. These results were plotted as a function of swimming velocity and the velocity corresponding to the blood lactate concentration of $4 \mathrm{mM}$ was determined by interpolation or extrapolation, as shown in Figure $2^{14}$. This intensity was arbitrarily chosen to represent the blood lactate response to submaximal swimming.

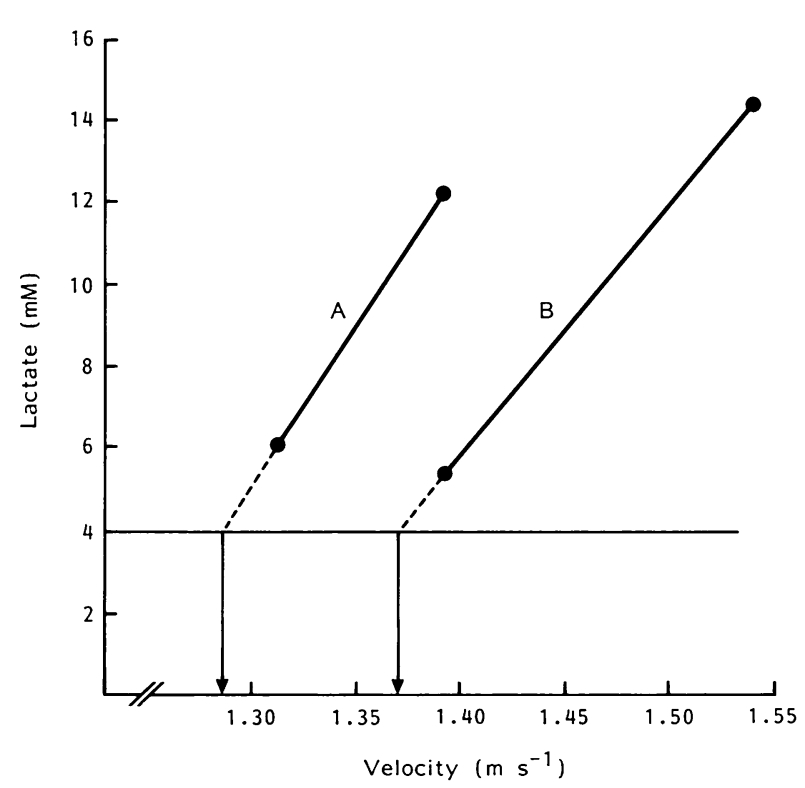

Figure 2. Blood lactate concentration related to swimming velocity for the same swimmers described in Figure 1. For both athletes the swimming velocity corresponding to a blood lactate concentration of $4 \mathrm{mM}$ was extrapolated. 
Descriptive data are presented as mean \pm standard deviation. To determine the capacity of the metabolic indices to predict swimming performance in the 400 metres freestyle event, multiple linear regression analysis with the maximal swimming speed as the dependent variable was used ${ }^{21}$. Since six metabolic indices were used as independent variables, the Bonferroni correction was applied and the level of probability required for significance was 0.008 (0.05 divided by the number of variables) ${ }^{22}$.

\section{Results}

Table 1 contains the average performance of the swimmers. The best time for the event varied between $4 \mathrm{~min} 19 \mathrm{~s}, 86$ hundreths, for the best swimmer and $4 \mathrm{~min} 56 \mathrm{~s}, 68$ hundreths, for the swimmer with the poorest result. In the submaximal trial, the swimmers attained a speed which ranged from 89 to 95 percent of the velocity attained in the maximal trial. These findings resulted in metabolic findings which allowed the appropriate interpolation or extrapolation of the variables for all swimmers.

Table 2 contains the results for $\dot{\mathrm{VO}}_{2} \max$ and submax, as well as the blood lactate concentration before and after each trial. It is of note that the blood lactate concentration before the maximal event is higher than the one before the submaximal event. This was probably due to the fact that blood lactate levels had not returned back to baseline during the 20 minute interval period between the events.

Table 3 shows the simple correlation coefficients for each of the metabolic indices and the maximal swimming velocity in the 400 metres event. Only the velocity corresponding to 85 percent of $\mathrm{VO}_{2}$ max and

Table 2. Metabolic data in 15 swimmers

\begin{tabular}{|c|c|c|c|}
\hline & Mean & $S D$ & Range \\
\hline $\begin{array}{l}\dot{\mathrm{V}} \mathrm{O}_{2} \text { submax }\left(\mathrm{l} \cdot \mathrm{min}^{-1}\right) \\
\dot{\mathrm{V}} \mathrm{O}_{2} \operatorname{submax}\left(\% \mathrm{~V} \mathrm{O}_{2} \max \right) \\
\dot{\mathrm{V}} \mathrm{O}_{2} \max \left(\mathrm{l} \cdot \min { }^{-1}\right) \\
\dot{\mathrm{V}} \mathrm{O}_{2} \max \left(\mathrm{ml} .[\mathrm{kg} \cdot \mathrm{min}]^{-1}\right) \\
\dot{\mathrm{V}} \mathrm{O}_{2} \max \left(\mathrm{ml} .[\mathrm{kgLBM} \cdot \min ]^{-1}\right)\end{array}$ & $\begin{array}{l}2.83 \\
81 \\
3.47 \\
56 \\
63\end{array}$ & $\begin{array}{l}0.50 \\
5 \\
0.53 \\
6 \\
6\end{array}$ & $\begin{array}{l}1.91-3.67 \\
75-92 \\
2.56-4.52 \\
45-62 \\
50-70\end{array}$ \\
\hline $\begin{array}{l}\text { Lactate pre-submax }(\mathrm{mM}) \\
\text { Lactate pre-max }(\mathrm{mM}) \\
\text { Lactate submax }(\mathrm{mM}) \\
\text { Lactate } \max (\mathrm{mM})\end{array}$ & $\begin{array}{r}1.6 \\
2.3 \\
5.7 \\
11.8\end{array}$ & $\begin{array}{l}0.4 \\
0.8 \\
2.0 \\
2.5\end{array}$ & $\begin{array}{l}1-2.5 \\
1.2-4.0 \\
3.1-9.8 \\
7.8-17.2\end{array}$ \\
\hline
\end{tabular}

Table 3. Correlation between maximal swimming velocity in the $\mathbf{4 0 0}$ metres freestyle and metabolic indices

\begin{tabular}{|c|c|c|c|}
\hline Index & $r$ & $r^{2}$ & $p$ \\
\hline $\begin{array}{l}\text { Velocity at } 85 \% \dot{V}_{2} \max \\
\text { Velocity at } 4 \mathrm{mM}\end{array}$ & $\begin{array}{l}0.90 \\
0.89\end{array}$ & $\begin{array}{l}0.81 \\
0.79\end{array}$ & $\begin{array}{l}<0.001 \\
<0.001\end{array}$ \\
\hline $\begin{array}{l}\text { Lactate max } \\
\dot{\mathrm{V}} \mathrm{O}_{2} \max \left(\mathrm{l} \cdot \mathrm{min}^{-1}\right) \\
\dot{\mathrm{V}} \mathrm{O}_{2} \max \left(\mathrm{ml} .[\mathrm{kg} \cdot \mathrm{min}]^{-1}\right) \\
\dot{\mathrm{V}} \mathrm{O}_{2} \max \left(\mathrm{ml} .[\mathrm{kgLBM} \cdot \mathrm{min}]^{-1}\right)\end{array}$ & $\begin{array}{r}0.42 \\
0.30 \\
-0.08 \\
0.07\end{array}$ & $\begin{array}{l}0.18 \\
0.09 \\
0.006 \\
0.005\end{array}$ & $\begin{array}{l}>0.05 \\
>0.05 \\
>0.05 \\
>0.05\end{array}$ \\
\hline
\end{tabular}

the velocity corresponding to the blood lactate concentration of $4 \mathrm{mM}$ correlated significantly to maximal swimming performance.

Figure 3 shows scattergrams for these associations. The maximal blood lactate concentration as well as the $\dot{\mathrm{VO}}_{2}$ max expressed in absolute values and relative to body composition did not correlate significantly to maximal swimming performance. Multiple linear regression analysis showed that when the velocity corresponding to 85 percent of $\mathrm{VO}_{2} \max$ and the velocity corresponding to the blood lactate concentration of $4 \mathrm{mM}$ were entered in the model, a multiple correlation coefficient of 0.91 was found $\left(\mathrm{r}^{2}\right.$ $=0.83, \mathrm{p}<0.001$ ) with the maximal swimming velocity. When the velocity corresponding to the blood lactate concentration of $4 \mathrm{mM}$ was added to the velocity corresponding to 85 percent of $\mathrm{VO}_{2} \max$ as a
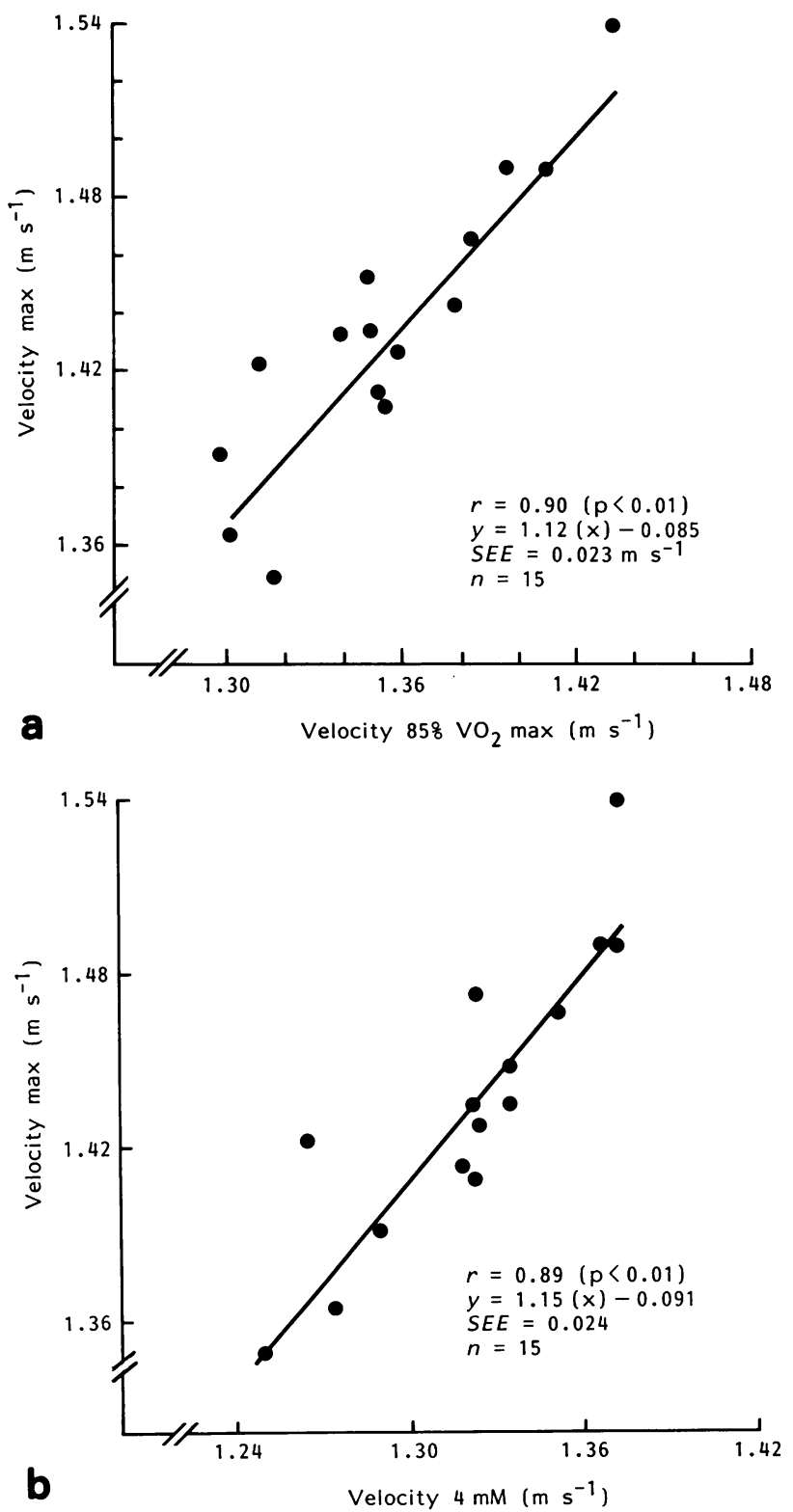

Figure 3. a: Relation between the swimming velocity corresponding to 85 percent of $\mathrm{VO}_{2}$ max and maximal velocity is depicted; b: Relation between the velocity corresponding to $4 \mathrm{mM}$ and the maximal swimming velocity is presented. 
second predictor, the predictibility did not increase significantly. Thus, both the velocity corresponding to 85 percent of $\mathrm{VO}_{2}$ max and the velocity corresponding to $4 \mathrm{mM}$ blood lactate concentration were found to be good isolated predictors of swimming performance in the $\mathbf{4 0 0}$ metres freestyle swimming event.

\section{Discussion}

In the 400 metres freestyle swimming event both aerobic and anaerobic energy releasing processes are activated. For this reason, it was our hypothesis that the maximal performarice in such an event should be related to metabolic indices representative of both processes. It was a surprise to find out that $\mathrm{VO}_{2} \max$ expressed in $1 . \mathrm{min}^{-1}$ and relative to body composition did not correlate to maximal swimming velocity in an event which lasts four to five minutes. Although the protocol used does not assure that actual $\mathrm{VO}_{2}$ max was really attained, the maximal blood lactate concentrations are suggestive of a maximal effort. Moreover, previous studies have validated such protocol for the determination of $\dot{\mathrm{VO}}_{2}$ $\max ^{10,13}$. Thus, we believe that the results are representative of the $\mathrm{VO}_{2}$ max during swimming for the athletes. Costill et al. ${ }^{10}$ have found a low, but significant, correlation coefficient $(r=0.47)$ between $\mathrm{VO}_{2}$ max and middle distance swimming performance. The fact that we found no significant association is probably related to the more homogeneous swimming performance of our atheletes, who had much better results when compared to the swimmers studied by Costill et al. ${ }^{\mathbf{1 0}}$.

The velocity corresponding to 85 percent of $\dot{\mathrm{VO}}_{2}$ max was shown to be highly correlated to swimming performance in the $\mathbf{4 0 0}$ metres freestyle swimming event. Thus, performance in such an event does not depend directly on the swimmer's $\mathrm{VO}_{2}$ max, but on the capacity to achieve higher velocities less taxing on his aerobic reserve. An illustration of the importance of submaximal exercise capacity is shown in Figure 1, where two swimmers are compared. Swimmer $A$ has a $\mathrm{VO}_{2}$ max higher than swimmer $\mathrm{B}$. However, the latter shows better economy, as demonstrated by a much lower $\mathrm{V}_{2}$ for a submaximal swimming velocity. To improve swimming performance, an athlete may increase his $\dot{\mathrm{V}} \mathrm{O}_{2} \max$ or improve his economy. Our data indicate that, at least for the group studied, economy is more important than maximal aerobic power.

The capacity to tolerate higher blood lactate concentrations is considered an important factor in the performance of athletic events which last four to five minutes ${ }^{15}$. However, in our sample, there was no significant correlation between maximal blood lactate concentration and maximal velocity. On the other hand, we found a strong correlation $(r=0.89)$ between the velocity corresponding to four $\mathrm{mM}$ blood lactate concentration and maximal swimming velocity. This finding is in agreement with the results of other authors who correlated lactate and ventilatory thresholds with running and cycling performance $^{1-8}$.
Likewise, Olbrecht et al. ${ }^{11}$ also found a strong correlation between the velocity corresponding to the blood lactate concentration of $4 \mathrm{mM}$ and the performance in a $\mathbf{3 0}$ minute swimming event. However, these authors studied sport events which lasted more than ten minutes, while we studied a much shorter event. Thus, our results expand on this subject, demonstrating that the swimming velocity corresponding to a blood lactate concentration of $4 \mathrm{mM}$ is a good predictor swimming performance in a relatively short lasting event.

As shown in Figure 2, an athlete may improve his swimming performance by reducing the blood lactate concentration at a given speed, or by tolerating higher maximal blood lactate concentrations. Several mechanisms may result in the reduction of submaximal blood lactate levels. The swimmer may increase his $\dot{\mathrm{VO}}_{2}$ max after training, thus a given velocity would represent a lower relative intensity, resulting in lower blood lactate levels. Or the swimmer could, after training, reduce the blood lactate concentration at a given swimming velocity without changing $\mathrm{VO}_{2}$ max ${ }^{23}$, by changes in the production and/or the metabolization of lactate at a certain percentage of $\dot{\mathrm{V}} \mathrm{O}_{2} \max ^{24}$.

Finally, the swimmer could improve his economy, reducing the energetic cost for a certain swimming velocity. The fact that both the velocity corresponding to 85 percent of $\mathrm{VO}_{2} \max$ and the velocity corresponding to $4 \mathrm{mM}$ blood lactate concentration were found to be good predictors of maximal swimming performance suggests that, at least for the swimmers in this study, swimming economy, which is a factor which contributes to both indices, is the most important determinant of swimming performance in the 400 metres freestyle swimming event. However, it is possible that, for groups of athletes with better swimming performance, like the ones studied by Mader et al. ${ }^{14}$, the adaptations related to lactate metabolism might be more important.

Although the methods used in the present experiments had been previously validated ${ }^{11-15}$, they have important limitations. The interpolation and extrapolation of the oxygen uptake curves are based on the assumption that, around the intensities studied, there is a linear relation between $\mathrm{VO}_{2}$ and swimming velocity, but $\mathrm{VO}_{2}$ increases curvilinearly with swimming velocity ${ }^{9}$. Moreover, the method also assumes that there is no plateau in $\dot{\mathrm{VO}}_{2}$ close to $\mathrm{VO}_{2}$ max. Likewise, the blood lactate concentration increases exponentially to increments in swimming velocity ${ }^{14}$. However, all our swimmers were studied at intensities above 75 percent of their $\dot{\mathrm{VO}}_{2}$ max, which resulted in blood lactate concentration higher than $3 \mathrm{mM}$, above the point where the most inclined deflections occur in the $\dot{\mathrm{VO}}_{2}$ and blood lactate curves $^{9,14}$. Thus, an assumption was made that the response was linear at those intensities for interpolation or extrapolation. These limitations indicate that future studies should evaluate a larger number of submaximal swimming velocities.

Another important limitation, which has not been considered in previous studies on the relationship between metabolic indices and maximal perform- 
ance, is the possibility of mathematical coupling between the independent and dependent variables ${ }^{25}$. This occurs when part of a relationship between the variables can be explained by a direct or indirect mathematical relationship. In this study, as well as in previous ones $3,7,8,11$, metabolic indices were expressed as the swimming velocity (or running velocity) at which the index was measured. Since the dependent variable is also expressed as the certain velocity, it is expected that the athlete who had the higher maximal velocity would also reach a certain metabolic index at a higher submaximal velocity. These comments, however, do not invalidate our findings or the conclusions of previous studies, but one should be aware that some of the relationships may be overestimated because of mathematical coupling ${ }^{25}$.

\section{Conclusion}

The present study demonstrates that 79 percent of the variability of the swimming performance in the 400 metres swimming event can be accounted for in the swimming velocity corresponding to 85 percent of $\dot{\mathrm{VO}}_{2}$ max or the velocity corresponding to a blood lactate concentration of $4 \mathrm{mM}$ obtained by a relatively simple testing procedure. Both metabolic indices are good isolated predictors of middle distance swimming performance, indicating that the success in the 400 metres freestyle swimming event largely depends on the capacity of the athlete to reach higher swimming velocities with low blood lactate concentrations and/or taxing a lower percentage of $\mathrm{VO}_{2} \max$.

\section{Acknowledgements}

Drs. Ribeiro and De Rose are CNPq scientists.

\section{References}

1 Barlow, K., Weltman, A., Schurrer, R. and Henritze, J. Prediction of maximal effort bicycle ergometer endurance performance Int J Sports Med 1985, 6, 190-196

2 Costill, D.L. Metabolic responses during distance running I Appl Physiol 1970, 28, 251-255

3 Farrel, P.A., Wilmore, J.H., Coyle, E.F., Billing, J.E. and Costill, D.L. Plasma lactate accumulation and distance running performance Med Sci Sports Exercise $1979,11,338-344$

4 LaFontaine, T.P., Londeree, B.R. and Spath, W.K. The maximal steady state versus selected running events Med Sci Sports Exercise 1981, 13, 190-191

5 McLellan, T.M. and Skinner, J.S. Submaximal endurance performance related to the ventilation thresholds Can I Appl Sports Sci 1985, 10, 81-87

6 Reybrouck, T., Ghesquiere, J., Cattaert, A., Fagard, R. and Amery, A. Ventilatory thresholds during shortand long-term exercise J Appl Physiol 1983, 55, 1694-1700
7 Sjodin, B. and Jacobs, I. Onset of blood lactate accumulation and distance running performance Int $J$ Sports Med 1981, 2, 23-26

8 Tanaka, K., Matsuura, Y., Matsuzaka, A., Hirakoba, K., Kumagai, S., Sun, S. and Asano, K. A longitudinal assessment of anaerobic threshold and distance running performance Med Sci Sports Expercise 1984, 16, 278-282

9 Pendergast, D.R., Di Prampero, P.E., Graig, A.B., Wilson, D.R. and Rennie, D.W. Quantitative analysis of the front crawl in men and women J Appl Physiol 1977, 43, 475-479

10 Costill, D.L., Kovaleski, D., Porter, D., Kirwan, J., Fielding, R. and King, D. Energy expenditure during front crawl swimming: predicting success in middledistance events Int J Sports Med 1985, 6, 266-270

11 Olbrecht, J., Madsen, O., Mader, A., Liesen, H. and Hollmann, W. Relationship between swimming velocity and lactic concentration during continuous and intermittent training exercises Int J Sports Med 1985, 6, 74-77

12 Costill, D.L. Practical problems in exercise physiology research Research Quarterly for Exercise and Sport 1985, 56, 378-384

13 Leger, L.A., Seliger, V. and Brassard, L. Backward extrapolation of $\mathrm{VO}_{2}$ max values from the $\mathrm{O}_{2}$ recovery curve Med Sci Sports Exercise 1980, 12, 24-27

14 Mader, A., Madsen, O. and Hollmann, W. Zur Beurteilung der lak- taziden Energiebereitstellung für Trainings- und Wettkampf- leistungen im Sportschwimmen Leistungssport 1980, 10, 263-268

15 Troup, J. Setting up a season using scientific training. A guide on how to apply $\mathrm{VO}_{2}$ and lactate measures in establishing a training schedule Swimming Technique 1986, May-July: 8-16

16 Scholander, P.P. Analyser for accurate estimation of respiratory gases in one half cubic centimeter samples J Biol Chem 1947, 167, 235-250

17 Consolazio, C.F., Johnson, R.E. and Pecora, L.J. 'Physiological measurements of metabolic functions in men' New York, McGraw, 1963

18 Montpetit, R.R., Leger, L.A., Lavoie, J.M. and Cazola, G.A. $\dot{\mathrm{VO}}_{2}$ peak during free swimming using the backward extrapolation of the $\mathrm{O}_{2}$ recovery curve Eur J Appl Physiol 1981, 47, 385-391

19 Faulkner, J.A. Physiology of swimming and diving. In Falls, H.B. (ed.) 'Exercise physiology' New York, Academic Press, 1968, p 417

20 Bergmeyer, H.U. 'Methods of enzymatic analysis' New York, Academic Press, 1974, pp 1464-1472

21 Kleinbaum, D.G. and Kupper, L.L. 'Applied regression analysis and other multivariate methods' North Scituate, Duxbury, 1978, p 131

22 Wallenstein, S., Zucker, C.L. and Fleiss, J.L. Some statistical methods useful in circulation research Cir Res 1980, 47, 1-9

23 Hurley, B.F., Hagberg, J.M., Allen, W.K., Seals, D.R., Young, J.C., Cuddihee, R.W. and Holloszy, J.O. The effect of training on blood lactate levels during submaximal exercise J Appl Physiol 1984, 56, 1260-1264

24 Brooks, G.A. Anaerobic threshold: review of the concept and directions for future research $\mathrm{Med} \mathrm{Sci}$ Sports Exercise 1985, 17, 22-31

25 Archie, J.P. Mathematical coupling of data Ann Surg 1981, 193, 296-303 